\title{
Formação de profissionais da educação no brasil: Ocurso de pedagogia em questão
}

\author{
Leda Scheibe \\ Márcia Ângela Aguiar"
}

\begin{abstract}
RESUMO: O objetivo deste artigo é apresentar subsídios para uma melhor compreensão da situação atual do curso de pedagogia no Ensino Superior brasileiro e das dificuldades enfrentadas para a implantação das novas diretrizes curriculares para esse curso. Iniciamos pela configuração do contexto em que se coloca o debate das diretrizes, no interior das alterações que sofre hoje esse grau de ensino, e com um breve histórico do curso de pedagogia no país. Destaca-se, em seguida, o processo de afirmação da identidade do profissional da educação e a construção da docência como patamar básico para a sua formação. Ao final, são apontadas as diretrizes que o momento histórico brasileiro indica para a formação do pedagogo.
\end{abstract}

Palavras-chave: Reforma educacional, formação de profissionais da educação, reforma do curso de pedagogia, Institutos Superiores de Educação, diretrizes curriculares

Introdução

Em primeiro lugar, é preciso considerar em que contexto se desestrutura/reestrutura a formação do pedagogo no Brasil. É com esse quadro

\footnotetext{
* Professora da Universidade Federal de Santa Catarina. Email: scheibe@cfh.ufsc.br

** Professora da Universidade Federal de Pernambuco. Email: marciangela@zipmail.com.br
} 
em evidência que tentaremos entender o movimento que estamos vivendo no processo de articulação de diretrizes curriculares para o curso de pedagogia.

O quadro a destacar inicialmente é o da reconfiguração mais geral da educação superior brasileira, no qual se encontra em curso uma reforma que se efetiva de modo bastante fragmentário, por meio de múltiplos instrumentos legais, como leis ordinárias, decretos, emendas constitucionais e mesmo medidas provisórias. Reis Silva Jr. e Sguissardi (1999) apontam como principais agentes desse movimento, entre outros, os seguintes: o Estado - especialmente o Poder Executivo, na figura dos Ministérios da Administração Federal e da Reforma do Estado (Mare) da Educação e Cultura (MEC) -, a Associação Brasileira das Mantenedoras (Abmes), a Associação Nacional das Universidades Particulares (Anup), a Associação Brasileira das Universidades Comunitárias (Abruc), o Conselho dos Reitores da Universidades Brasileiras (Crub), a Associação de Dirigentes de Instituições Federais de Ensino Superior (Andifes) e a Associação Nacional dos Docentes do Ensino Superior (Andes). Esses autores destacam, no entanto, que as alterações formuladas no âmbito do governo tendem a seguir as orientações de organismos multilaterais, como é o caso do Bird/Banco Mundial, do que de se pautar por amplas discussões com os segmentos envolvidos no processo. Diante da iniciativa hegemônica oficial, as entidades da sociedade civil que representam segmentos da educação superior brasileira com interesses diferenciados, e muitas vezes inclusive antagônicos entre si, encontram-se, portanto, em "posição mais reativa do que propositiva" (p. 34).

Há hoje um conjunto significativo de alterações no ensino superior brasileiro - que abrange desde o processo de transformação das instituições de ensino superior em organizações sociais, ou seja, em entidades públicas de natureza privada, até a implementação de uma série de medidas de ordem legal tais como o congelamento de salários, escolha de dirigentes das universidades, procedimentos para os processos de avaliação dos cursos e das instituições de ensino superior - que é conseqüência de uma ação coordenada com o Congresso Nacional, no sentido de garantir a implementação da LDB, em especial de aspectos que constavam no projeto da LDB de Darcy Ribeiro.

Como elemento desencadeador da reconfiguração do ensino superior, tem sido destacada a crise em que se encontraria o sistema federal de ensino superior, por não absorver toda a demanda e por não 
preparar adequadamente os estudantes para o mercado de trabalho. Nesse sentido, são apontados como fatores: o modelo das universidades de pesquisa como insustentável, por ser muito oneroso para o poder público; a inviabilidade de financiamento das instituições públicas pelo governo central; o excessivo envolvimento do Estado nas questões de ensino superior; a falta de "qualidade e equidade". A superação destas e de outras questões coloca-se na base das várias medidas legais já postas em prática.

A generalidade e a flexibilidade que caracterizam a nova LDB possibilitam as reformas pontuais apontadas. É o caso do Decreto 2.306 de 1997, que regulamenta a existência de uma tipologia inédita para o sistema de ensino superior brasileiro: Instituições de Ensino Superior (IES) públicas, IES privadas sem fins lucrativos e IES privadas com fins lucrativos. Quanto à sua organização acadêmica, as instituições de ensino superior do sistema federal de ensino passaram a ser classificadas em: a) universidades; b) centros universitários; c) faculdades integradas; d) faculdades; e) institutos superiores ou escolas superiores. Instaurouse com essa legislação a distinção entre universidades de pesquisa e universidades de ensino e normatizou-se uma hierarquia no interior do ensino superior que, certamente, demandará cada vez mais em reivindicações diferenciadas para cada setor. Destaque-se aí a questão da formação de professores. Estabeleceu-se como locus privilegiado para essa formação o nível mais baixo da hierarquia. Um caminho que, independentemente do setor ao qual se vincula (público, particular, comunitário), deverá ser o menos oneroso.

A questão evidentemente é complexa, e convive com a necessidade de estabelecer um sistema nacional para a formação de professores no país que dê conta da capacitação de amplos contingentes necessários para suprir a escolarização básica nacional. A trajetória da discussão que propiciou a normatização dos Institutos Superiores de Educação já demonstrou a complexidade apontada e favoreceu, ao final, uma posição mais aberta, concebendo uma diferenciação importante ao estabelecer, no seu art. $3^{\circ}$, que esses institutos poderão ser organizados como instituto superior propriamente dito ou em faculdade, ou em faculdade integrada ou em escola superior, com direção ou coordenação do conjunto das licenciaturas ministradas (alínea I); como unidade de uma universidade ou centro universitário, com direção ou coordenação do conjunto das licenciaturas ministradas (alínea II); ou ainda como coordenação única de cursos ministrados em diferentes unidades de uma mesma instituição (alínea III) 
(Resolução CP № 1, de 30/09/1999). O significado dessa abertura, entendemos, é o de que um sistema unificado para a formação de professores no país não implica necessariamente um modelo único.

É nesse contexto de reconfiguração do ensino superior brasileiro que se coloca o debate a respeito das novas diretrizes para o curso de pedagogia. Já na LDB (Lei n 9.394/96) o problema ficou explicitado, quando essa lei criou o curso normal superior destinado à formação de docentes para a educação infantil e para as primeiras séries do ensino fundamental (art. 63). Esse curso foi previsto para compor os Institutos Superiores de Educação. A única referência, na lei, ao curso de pedagogia, está no art. 64 , que diz que "A formação de profissionais de educação para administração, planejamento, inspeção, supervisão e orientação educacional para a educação básica será feita em cursos de graduação em pedagogia ou em nível de pós-graduação, a critério da instituição de ensino, garantida, nesta formação, a base comum nacional". A lei, portanto, não extinguiu o curso de pedagogia. Fica, porém, a questão de como interpretar o curso de pedagogia de agora em diante, se esse curso passou, sobretudo nos últimos anos, a formar justamente o professor para as séries iniciais do ensino fundamental e para a educação infantil?

\section{Um breve histórico do curso}

O curso de pedagogia foi criado no Brasil como conseqüência da preocupação com o preparo de docentes para a escola secundária. Surgiu junto com as licenciaturas, instituídas ao ser organizada a antiga Faculdade Nacional de Filosofia, da Universidade do Brasil, pelo Decreto-lei no 1190 de 1939. Essa faculdade visava à dupla função de formar bacharéis e licenciados para várias áreas, entre elas, a área pedagógica, seguindo a fórmula conhecida como " $3+1$ ", em que as disciplinas de natureza pedagógica, cuja duração prevista era de um ano, estavam justapostas às disciplinas de conteúdo, com duração de três anos. Formava-se então o bacharel nos primeiros três anos do curso e, posteriormente, após concluído o curso de didática, conferiase-lhe o diploma de licenciado no grupo de disciplinas que compunham o curso de bacharelado.

Como bacharel, o pedagogo poderia ocupar cargo de técnico de educação, do Ministério de Educação, campo profissional muito vago 
quanto às suas funções. Como licenciado, seu principal campo de trabaIho era o curso normal, um campo não exclusivo dos pedagogos, uma vez que, pela Lei Orgânica do Ensino Normal, para lecionar nesse curso era suficiente o diploma de ensino superior.

Apesar de alguns retoques feitos na sua estrutura em 1962, esse quadro do curso de pedagogia perdurou até 1969, quando este foi reorganizado, sendo então abolida a distinção entre bacharelado e licenciatura, e criadas as "habilitações", cumprindo o que acabava de determinar a lei $n^{\circ}$ 5540/68. A concepção dicotômica presente no modelo anterior permaneceu na nova estrutura, assumindo apenas uma feição diversa: o curso foi dividido em dois blocos distintos e autônomos, desta feita, colocando de um lado as disciplinas dos chamados fundamentos da educação e, de outro, as disciplinas das habilitações específicas. O curso de pedagogia passou então a ser predominantemente formador dos denominados "especialistas" em educação (supervisor escolar, orientador educacional, administrador escolar, inspetor escolar, etc.), continuando a ofertar, agora na forma de habilitação, a licenciatura "Ensino das disciplinas e atividades práticas dos cursos normais", com possibilidade ainda de uma formação alternativa para a docência nos primeiros anos do ensino fundamental.

O Parecer CFE nํ2 252/69, incorporado à Resolução CFE nํ2/69, que fixou os mínimos de conteúdo e duração a serem observados na organização do curso de pedagogia, até hoje em vigor, baseou-se na concepção de que as diferentes habilitações deveriam ter uma base comum de estudos, constituída por matérias consideradas básicas à formação de qualquer profissional na área, e uma parte diversificada, para atender às habilitações específicas. A base comum foi composta pelas seguintes disciplinas: sociologia geral, sociologia da educação, psicologia da educação, história da educação, filosofia da educação e didática. A parte diversificada, para cada uma das habilitações, ficou assim estabelecida:

- $\quad$ para a habilitação "Ensino das disciplinas e atividades práticas dos cursos normais", as seguintes matérias: estrutura e funcionamento do ensino de $1^{\circ}$ grau, metodologia do ensino de $1^{\circ}$ grau, prática de ensino na escola de $1^{\circ}$ grau (estágio);

- para a habilitação "Orientação educacional", as matérias: estrutura e funcionamento do $1^{\circ} \mathrm{grau}$, estrutura e funcionamento do ensino de $2^{\circ}$ grau, princípios e métodos de orientação educacional, orientação vocacional e medidas educacionais; 
- para a habilitação "Administração escolar", as matérias: estrutura e funcionamento do ensino de $1^{\circ}$ grau, estrutura e funcionamento do ensino de $2^{\circ}$ grau, princípios e métodos de administração escolar e estatística aplicada à educação;

para a habilitação "Supervisão escolar", as matérias: estrutura e funcionamento do ensino de $1^{\circ}$ grau, estrutura e funcionamento do ensino de $2^{\circ}$ grau, princípios e métodos de supervisão escolar e currículos e programas;

- para a habilitação "Inspeção escolar", as matérias selecionadas foram as seguintes: estrutura e funcionamento do ensino de $1^{\circ}$ grau, estrutura e funcionamento do ensino de $2^{\circ}$ grau, princípios e métodos de inspeção escolar e legislação do ensino.

A legislação anteriormente referida fixou que o título único a ser conferido pelo curso de pedagogia passava a ser o de licenciado, por entender que todos os diplomados poderiam ser, em princípio, professores do curso normal. $\mathrm{O}$ direito ao magistério primário já se apresentou então como um impasse: "quem pode mais pode também menos"? Quem prepara o professor primário também pode ser professor desse nível de ensino? A formação indispensável ao exercício desse magistério não ficava garantida. Fixaram-se então algumas exigências para a aquisição desse direito.

O percurso apresentado de forma muito breve é importante para entender o debate que se aprofundou nas décadas seguintes a respeito da identidade do pedagogo no Brasil, identidade esta fragmentada por um currículo e por uma profissionalização insatisfatórios para realizar uma tarefa efetivamente educativa:

(...) não se pode formar o educador com partes desconexas de conteúdos, principalmente quando essas partes representam tendências opostas em educação: uma tendência generalista e uma outra tecnicista. Essas tendências (...) a primeira quase que exclusivamente na parte comum, considera que ela se caracteriza, "grosso modo", pela desconsideração da educação concreta como objeto principal e pela centralização inadequada nos fundamentos em si (isto é, na psicologia e não na educação; na filosofia e não na educação, e assim por diante). A segunda, por sua vez, é identificada com as habilitações, consideradas como especializações fragmentadas, obscure- 
cendo seu significado de simples divisão de tarefas do todo que é a ação educativa escolar. (Bissoli da Silva 1999, p. 70)

Foi na base da identidade profissional de todo educador que se centrou a grande e rica discussão que passamos a focalizar.

\section{Base docente: Uma questão fechada ou a afirmação da identidade do profissional da educação?}

Nos debates sobre o curso de pedagogia que vêm ocorrendo desde o final da década de 1970, uma temática central sempre esteve em foco: a questão da base comum nacional. Essa expressão foi cunhada pelo Movimento Nacional de Formação do Educador, e explicitada pela primeira vez no Encontro Nacional para a "Reformulação dos Cursos de Preparação de Recursos Humanos para a Educação“, realizado em Belo Horizonte, em novembro de $1983,{ }^{1}$ justo no momento em que as forças sociais empenhadas na luta pela redemocratização do país estavam se organizando em todos os campos, inclusive no campo educacional. Aliás, é bom lembrar que, após as eleições de 1982, alargava-se o anseio por participação entre os educadores, e diversas experiências de participação passaram a ocorrer em vários estados e municípios, a exemplo do I Congresso Mineiro de Educação, do I Encontro de Professores de Primeiro Grau do Estado do Rio de Janeiro e do Fórum de Educação do Estado de São Paulo. No plano nacional, os educadores engajavam-se na luta pela reformulação do curso de pedagogia e das licenciaturas, contrapondo-se à imposição de reformas definidas nas instâncias oficiais.

No Encontro de Belo Horizonte foi firmado o princípio de que a docência constitui a base da identidade profissional de todo educador. Preocupado com a repercussão dessa tese nos meios educacionais e, também, contrário à mesma, o representante do Inep convocou especialistas e a coordenadora da Comissão Nacional de Reformulação dos Cursos de Formação do Educador (Conarcfe) ${ }^{2}$ para discutir a questão. Assim, o Instituto Nacional de Estudos e Pesquisas Pedagógicas (Inep/MEC) organizou uma mesa-redonda sobre "Natureza e especificidade da educação", ocorrida em 5 de julho de 1994, na qual estiveram em pauta visões diferenciadas sobre o curso de pedagogia e a formação do educador, assumidas, especialmente, pelos professores Demerval Saviani e Moacir Gadotti, que polemizavam a questão do saber "doxológico" x saber "epistemológico". 
É curioso observar que, em face da mobilização dos educadores em prol da reformulação do curso de pedagogia, tendo a docência como base, um órgão oficial do governo procure introduzir na agenda a questão da especificidade do curso de pedagogia. Cabe perguntar: por que a questão da identidade vai ser colocada no debate pelo Inep? Essa era uma pergunta que Gadotti (1985) também formulava à época. Esse autor lembrava com propriedade que a escola, como a Igreja, é uma instituição histórica. Como tal, essas instituições "assumem funções de acordo com o momento histórico. E quem poderá determinar a função, a natureza e a especificidade dessas instituições, se não o próprio movimento histórico? O que é, então, específico? O específico depende de cada momento histórico?". E concluía "colocar a questão da especificidade, deslocada de sua compreensão histórica, é" (...) introduzir disfarçadamente, portanto, ideologicamente, na escola, o gérmen do esvaziamento do seu papel social e político, reduzindo-a ao cumprimento de suas funções técnicas" (pp. 147-148).

Registre-se que nessa mesa-redonda foi pela primeira vez expresso esse princípio norteador da formação do educador através da Conarcfe, tendo sido objeto da seguinte manifestação:

no tocante à reformulação dos cursos de pedagogia e licenciatura, o projeto mais amplamente debatido é o que está parcialmente consubstanciado no documento final do Encontro Nacional de Belo Horizonte. É um ponto obrigatório de referência, fruto de seis anos de debates, síntese de um esforço nacional por uma educação democrática.

É preciso retomar essa luta e, se possível, dar um salto qualitativo na concretização das metas aí expostas. Os educadores brasileiros esperam que o Inep, seguindo as pegadas do seu fundador, o eminente educador Anísio S. Teixeira, se engaje na luta pela reformulação dos cursos de formação do educador, na linha diretriz traçada neste documento. É a essa campanha que devemos dar continuidade. (Idem, p. 168)

Essa questão foi retomada na primeira avaliação pública feita pela Conarfce concernente ao movimento, durante a $36^{\text {a }}$ Reunião da SBPC, em 1994, ocasião em que se apontavam os diversos entendimentos sobre a base comum nacional: 
a) A base comum seria a garantia de uma prática comum nacional a todos os educadores, qualquer que seja o conteúdo específico de sua área de atuação. Assim concebida, ela supõe que, ao longo de todo o processo de formação, isto é, durante todo o curso, em todas as disciplinas pedagógicas, e principalmente nas de conteúdo específico, busque-se estimular a capacidade questionadora da informação recebida e a sua crítica. Esta base comum deve contemplar estudos comuns a todas as licenciaturas, objetivando formar o hábito da reflexão sobre as questões educacionais no contexto mais amplo da sociedade brasileira e a capacidade crítica do educador, em face da realidade em que vai atuar. Para efetivá-la, sugerem-se 'linhas de ação' comuns a todas as licenciaturas, tais como ciclos de estudos, redefinição da orientação das disciplinas pedagógicas e de conteúdo específico, etc. (...) Seria necessário assegurar, institucionalmente, um espaço para a sua avaliação, já que a base comum é construída durante o processo tendo, portanto, caráter histórico e evolutivo.

b) A base comum seria considerada como uma diretriz que envolve uma concepção básica de formação do educador e que se concretiza através da definição de um corpo de conhecimento fundamental. Essa concepção básica de formação do educador deve traduzir uma visão de homem situado historicamente, uma concepção de educador comprometido com a realidade do seu tempo e com o projeto de uma sociedade justa e democrática.

c) A base comum às várias licenciaturas deve principalmente destinar-se ao compromisso político do educador, o que implica a formação da consciência crítica. Daí ser necessário incluir um corpo de conhecimento fundamental, que aprofunde o domínio filosófico, sociológico, político e psicológico do processo educativo, dentro de uma abordagem crítica, que explore o caráter científico da educação, tomando como referência o contexto socioeconômico e político brasileiro (Revista de Ensino de Física no 1, 1984, pp. 61$62)$.

Outras dimensões foram atribuídas, ao longo do tempo, à "base comum nacional" no âmbito da Conarcfe e atual Anfope (Associação Nacional pela Formação dos Profissionais da Educação), a saber: "princípio que permita avançar na formação dos profissionais do ensino ne- 
cessários à luta, no plano educativo, pela transformação da sociedade brasileira" (1986); "ponto de referência para a articulação curricular de cada instituição formadora do profissional da educação" (1990); "instrumento de luta e norte para a reformulação dos cursos de formação do educador" (1992).

Nesse movimento nacional sempre esteve presente a idéia de que não seria possível reformular os cursos de pedagogia independentemente das licenciaturas, e que tal reformulação implicava profunda mudança no próprio sistema educacional. Tal compreensão levou o movimento a uma formulação que desde então não só tem norteado a ação da Anfope, como constitui um fator aglutinador de educadores e instituições de ensino que se posicionam nessa perspectiva: a defesa de uma política global de formação dos profissionais da educação que contemple formação inicial, carreira, salário e formação continuada.

No atual cenário, pós-LDB, demarcam-se com nitidez os novos campos de disputa, reacendendo-se as lutas em torno do novo locus e da configuração dos cursos de formação dos profissionais da educação. A introdução na LDB dos Institutos Superiores de Educação (ISE) abriu espaço para que as propostas que não tiveram condições históricas de se impor no debate nacional ressurgissem travestidas em forma de lei. A regulamentação proposta pelo CNE e homologada pelo Ministro da Educação dispôs que esses institutos "de caráter profissional" poderiam incluir:

a) Curso Normal Superior, para licenciatura de profissionais em educação infantil e de professores para os anos iniciais do ensino fundamental;

b) cursos de licenciatura destinados à formação de docentes dos anos finais do ensino fundamental e do ensino médio;

c) programas de formação continuada, destinados à atualização de profissionais da educação básica nos diversos níveis.

Com isso, foram dadas as condições para uma nova formatação dos cursos de licenciatura e de pedagogia, com sérias implicações para a formação qualificada de professores e demais profissionais da educação. No caso do curso de pedagogia, rompe-se, na prática, com a visão orgânica da formação docente que vinha sendo construída no país nas últimas décadas. Acentua-se, por imposição legislativa, a dicotomia en- 
tre a formação para atuar na educação infantil e séries iniciais do ensino fundamental e a destinada às séries finais desse nível de ensino e do ensino médio. Impõe-se tal dicotomia no interior do locus de formação dos profissionais da educação, além de se atribuir aos institutos a prerrogativa da formação dos professores no setor privado. Com isso, aplaina-se o caminho para o esvaziamento do curso de pedagogia e para o sucesso das propostas que visam dele retirar a base da docência, transformando-o na prática em um bacharelado.

Em relação às outras licenciaturas, o movimento é similar: interrompem-se as experiências de formação de professores compartilhadas pelos institutos e faculdades de educação em curso no país, e forçamse as instituições de ensino superior privadas a criar os Institutos Superiores de Educação, caso optem por oferecer cursos de licenciatura. Essa medida também cerceia as experiências e as novas propostas de cursos de licenciaturas que estão sendo conduzidas por aquelas instituições privadas que têm compromisso com a qualidade da formação e com a cidadania dos estudantes.

Com esse posicionamento, o Conselho Nacional de Educação (em que pese a posição de conselheiros que se opunham a esse encaminhamento) deu seu aval às políticas ministeriais que, seguindo a orientação dos organismos internacionais, darão nova configuração à formação dos profissionais da educação no Brasil. Tais medidas são saudadas por muitos com euforia, sobretudo pelos "homens de negócios da educação", que vislumbram o "filão" que representa a oferta de cursos de licenciatura de curta duração, uma vez que "o aproveitamento da formação e experiências anteriores em instituições de ensino e na prática profissional" (Res. CP $n^{\circ} 1$, de 30/9/99) darão respaldo legal à oferta de cursos ministrados em tempo recorde com carga horária diminuta. Com tais medidas, o governo federal cria um nicho no mercado para o setor privado, o que já pode ser visualizado pela corrida de determinados grupos empresariais dispostos a entrar nessa seara que lhes parece promissora.

Provavelmente, diante desse quadro, pouco adiantará a oferta de melhores cursos pelas universidades públicas, em especial pelas federais, com tempo suficiente para uma formação qualificada, tendo em vista que os estudantes não resistirão ao fato de que seus colegas poderão diplomar-se até mesmo na metade do tempo, em cursos semelhantes, com a possibilidade de ingresso mais cedo no disputado mercado de trabalho. Dessa forma, o provável esvaziamento e a baixa demanda por tais cursos constituirão os fatores determinantes para a retirada das universidades 
públicas desse campo da formação dedicando-se, prioritariamente, a outras áreas profissionais tidas como mais nobres e promissoras. Confirmando-se tal hipótese, disso resultará o rebaixamento da qualificação dos docentes da educação básica, alijados de centros importantes de produção dos conhecimentos científico-tecnológicos, situação certamente não evidenciada nas estatísticas que o governo poderá apresentar aos credores internacionais. Os prejuízos acadêmicos que poderão advir a toda uma geração de alunos da escola básica constitui motivo suficiente para que as forças organizadas da sociedade tentem reverter tal processo, influindo nos rumos desses institutos.

\section{Pedagogo e não "o especialista": Novas diretrizes para uma formação historicamente situada}

Um dos fatores que impulsionou o surgimento do movimento de reformulação dos cursos de licenciatura foi, sem dúvida, o repúdio à proposta de formação do "especialista no professor" no curso de pedagogia, tendo em vista que essa formação se ancorava numa visão reducionista e tecnicista de escola e de educador, questão amplamente discutida por vários autores. Não obstante, diversos cursos no país continuaram mantendo a mesma estrutura curricular, formando unicamente o especialista em administração escolar, em supervisão escolar e em orientação educacional, atendo-se apenas ao mínimo fixado pela Resolução CFE nº 2/69, com pequenas variações. Parte significativa desses cursos passava ao largo do debate a respeito das transformações que vêm ocorrendo no mundo da produção e do trabalho e nas formas de sociabilidade vigentes.

Por outro lado, a crítica produzida nos últimos anos bem como as experiências curriculares implementadas contribuíram decisivamente para a reformulação de muitos cursos, atualizando-se conteúdos e introduzindo-se novas perspectivas. Certamente, esse é um dado importante para qualquer avaliação ampliada que se faça a respeito. Vale também ressaltar que são vários os projetos de novos cursos de pedagogia encaminhados a SESu/MEC que apresentam componentes curriculares inovadores e contemporâneos. No entanto, tal tendência, que começou a se configurar nas propostas de abertura de novos cursos ou mesmo no processo de reconhecimento, corre o risco de ser descaracterizada por iniciativa do próprio MEC e do CNE, em decorrência da nova situação 
criada pelos Institutos Superiores de Educação e da suspensão da análise dos processos dos cursos de pedagogia voltados para a docência. Observadas as conseqüências dessas medidas, verifica-se que as instituições de ensino superior foram induzidas a apresentar propostas curriculares que contemplem as antigas habilitações em detrimento da formação docente, como forma única de obter aprovação de seus cursos nas instâncias oficiais.

O debate sobre a formação do educador no curso de pedagogia expressa hoje o conflito de posições teórico-metodológicas, epistemológicas. Na tentativa de mediar o processo, a Comissão de Especialistas de Ensino de Pedagogia, ${ }^{3}$ com base na análise de propostas de formação do profissional de educação, oriundas de mais de 500 instituições de ensino superior do país e nas contribuições das diversas entidades do campo educacional (Anped, Anfope, Anpae, Fórum dos Diretores de Faculdades de Educação), apresentou uma proposta de diretrizes curriculares a ser encaminhada ao Conselho Nacional de Educação.

Essa comissão assumiu a tese de que o curso de pedagogia destina-se à formação de um "profissional habilitado a atuar no ensino, na organização e na gestão de sistemas, unidades e projetos educacionais e na produção e difusão do conhecimento, em diversas áreas da educação, tendo a docência como base obrigatória de sua formação e identidade profissional". Assim, esse pedagogo poderá atuar na docência na educação infantil, nas séries iniciais do ensino fundamental e nas disciplinas de formação pedagógica do nível médio. E ainda na organização de sistemas, unidades, projetos e experiências educacionais escolares e não-escolares; na produção e difusão do conhecimento científico e tecnológico do campo educacional; nas áreas emergentes do campo educacional.

Com essa formulação, contemplam-se os campos de atuação do pedagogo, que tendo como fulcro a formação docente, será chamado a exercer papel importante em outras funções do campo educacional. Entende-se que tal perspectiva rompe com a tradição tecnicista de separar o saber e o fazer, a teoria e a prática. E aí cabe um papel importante às instituições de ensino superior que poderão ofertar uma formação que respeite a sua vocação, o seu interesse, a demanda local e sua função social.

Essas concepções estão na base da organização da estrutura curricular proposta que abrange duas partes intrinsecamente relacionadas: os conteúdos básicos e a parte diversificada ou de aprofundamento. A primeira parte engloba "um núcleo de conteúdos básicos, articuladores 
da relação teoria e prática, considerados obrigatórios pelas IES para a organização de sua estrutura curricular e relativos:

a) ao contexto histórico e sociocultural, compreendendo os fundamentos filosóficos, históricos, políticos, econômicos, sociológicos, psicológicos e antropológicos necessários para a reflexão crítica nos diversos setores da educação na sociedade contemporânea;

b) ao contexto da educação básica, compreendendo:

1. o estudo dos conteúdos curriculares da educação básica escolar;

2. os conhecimentos didáticos; as teorias pedagógicas em articulação com as metodologias; tecnologias de informação e comunicação e suas linguagens específicas aplicadas ao ensino;

3. o estudo dos processos de organização do trabalho pedagógico, gestão e coordenação educacional;

4. o estudo das relações entre educação e trabalho, entre outras, demandadas pela sociedade;

c) ao contexto do exercício profissional em âmbitos escolares e nãoescolares, articulando saber acadêmico, pesquisa e prática educativa." (Proposta de Diretrizes Curriculares de Pedagogia - 6/ 5/1999, http://www.mec.gov.br/sesu/diretriz.htm)

A outra parte diz respeito aos tópicos de estudo de aprofundamento e diversificação da formação. A Comissão de Especialistas entendeu ser necessária a diversificação na formação do pedagogo, para atender às diferentes demandas sociais e para articular a formação aos aspectos inovadores que se apresentam no mundo contemporâneo. Tal diversificação "pode ocorrer através do aprofundamento de conteúdos da formação básica e pelo oferecimento de conteúdos voltados às áreas de atuação profissional priorizadas pelo projeto pedagógico da IES" (idem). É importante também destacar que, se respeitado o princípio de flexibilização curricular, as diferentes modalidades podem ser concomitantes, complexificando-se e verticalizando-se de acordo com o desenvolvimento do curso.

Considerando a necessária flexibilização do currículo, dois outros componentes foram destacados: os estudos independentes e as práticas pedagógicas. Propõe-se que as instituições de ensino superior estabeleçam "mecanismos de aproveitamento de conhecimentos, adquiridos pelo 
estudante, através de estudos e práticas independentes, desde que atendido o prazo mínimo, estabelecido pela instituição, para a conclusão do curso" (idem). Para tanto, podem ser reconhecidos diversos tipos de atividades, a saber: monitorias e estágios; programas de iniciação científica; estudos complementares; cursos realizados em áreas afins; integração com cursos seqüenciais correlatos à área; participação em eventos científicos no campo da educação; outros" (idem).

A prática pedagógica, por sua vez, é configurada como um trabalho coletivo da instituição, fruto de seu projeto pedagógico, o que implica que todos os professores responsáveis pela formação do pedagogo deverão participar, em diferentes níveis, da formação teórico-prática de seu aluno. Nesse sentido, a relação teoria e prática será considerada como eixo articulador da produção do conhecimento na dinâmica do currículo.

A prática pedagógica expressa-se mediante três modalidades. A primeira modalidade, percebida como instrumento de integração do aluno com a realidade social, econômica e do trabalho de sua área/curso, possibilita a interlocução com os referenciais teóricos do currículo. Pretende-se que seja iniciada nos primeiros anos do curso e acompanhada pela coordenação docente da instituição de ensino superior. Essa modalidade de estágio deve permitir a participação do aluno em projetos integrados, favorecendo a aproximação entre as ações propostas pelas disciplinas/áreas/atividades.

A segunda modalidade de prática pedagógica, como instrumento de iniciação à pesquisa e ao ensino, na forma de articulação teoria-prática, considera que a formação profissional não se desvincula da pesquisa. A reflexão sobre a realidade observada gera problematizações e projetos de pesquisa entendidos como formas de iniciação à pesquisa educacional.

A terceira modalidade de estágio, destinada à iniciação profissional, deve ocorrer nas escolas e unidades educacionais, nas atividades de observação, regência ou participação em projetos, como um "saber fazer" que busca orientar-se por teorias pedagógicas para responder às demandas colocadas pela prática pedagógica. Estará presente desde os primeiros anos do curso, configurando a prática pedagógica necessária ao exercício profissional.

A conjugação dessas três modalidades de articulação teoria-prática observará o art. 65 da LDB: prática de ensino de no mínimo 300 horas. 
Evidentemente, a concretização da proposta de um novo curso de pedagogia calcado nessas orientações requer tempo dos professores e dos estudantes para pesquisas, leituras, participação em eventos e projetos variados, além da elaboração de um trabalho conclusivo de curso que sintetize suas experiências acadêmicas. Tal perspectiva exige que a carga horária do curso venha a ser compatível com a realização das atividades didáticas obrigatórias e optativas, laboratórios e práticas pedagógicas. Nessa ótica, a expectativa é de que o curso seja ministrado com 3.200 horas-aula, com duração total de quatro anos, atendendo inclusive às definições legais quanto ao cumprimento dos 200 dias letivos.

\title{
Para concluir...
}

Outras questões colocam-se para a atual discussão curricular. $O$ currículo, segundo Grundy, "não é um conceito, mas uma construção cultural. Isto é, não se trata de um conceito abstrato que tenha algum tipo de existência fora e previamente à experiência humana. É, antes, um modo de organizar uma série de práticas educativas" (apud Sacristán 1998, p. 14). O currículo é, portanto,

\begin{abstract}
expressão do equilíbrio de interesses e forças que gravitam sobre o sistema educativo num dado momento, enquanto que através deles se realizam os fins da educação no ensino escolarizado. (...) O currículo, em seu conteúdo e nas formas através das quais se nos apresenta aos professores e aos alunos, é uma opção historicamente configurada, que se sedimentou dentro de uma determinada trama cultural, política, social e escolar; está carregado, portanto, de valores e pressupostos que é preciso decifrar. (Idem, p. 17)
\end{abstract}

O processo que estamos vivendo de articulação das diretrizes curriculares para a formação do pedagogo evidencia a pertinência das colocações dos autores citados: mostra que é um processo de conciliação de forças.

Quais são as forças que é preciso conciliar? Aprovou-se na nova LDB duas proposições fundamentais para o atual embate: a pri- 
meira diz respeito à necessária formação do professor em nível superior; a segunda refere-se à criação dos cursos normais superiores. A primeira proposição, sem dúvida, atende a reivindicações do movimento dos educadores por melhor nível e qualidade na escolarização brasileira. A segunda proposição baseia-se numa indicação vinculada à distinção inédita estabelecida para o ensino superior brasileiro, já referenciada nesse texto, quanto à organização acadêmica desse ensino. O ensino superior estrutura-se hierarquicamente; vamos conviver com diferentes categorias de ensino superior, certamente vinculadas à valorização profissional. A formação de professores através dos Institutos Superiores de Educação e do Curso Normal Superior como curso fundamental destes Institutos estrutura-se num patamar de menor valorização. À intenção de melhor qualificação do professor, tornando-a competência do ensino superior, acoplou-se a possibilidade de redução desse nível de ensino não apenas no seu tempo de integralização, mas também nas qualificações para a sua realização.

Uma posição propositiva, neste momento, deve ser também reativa: é importante recolocar o papel da universidade na formação dos professores. Entender o curso de pedagogia desvinculado da formação de professores, num entendimento que vem sendo assumido por acadêmicos e por representantes do Conselho Nacional de Educação, é deixar de contemplar a complexidade da história do curso e da formação de professores no país. A trajetória peculiar que assumiu o curso de pedagogia no Brasil, como espaço também de formação de professores para a educação infantil e séries iniciais do ensino fundamental, não apenas tem o papel de vincular essa formação ao ensino universitário, mas principalmente e ainda o de superar a dicotomia que desvincula teoria e prática, pensar e fazer, conteúdo e forma na área do conhecimento e da prática educacional.

O curso de pedagogia, no percurso de sua existência, talvez pela própria amplitude da área que o denomina, foi se amoldando aos interesses hegemônicos dos projetos educativos vigentes. A opção histórica que faz sentido configurar neste momento é aquela que resulta de um trabalho de mediação que não apenas contemple uma discussão conceitual, mas também a complexidade histórica do curso, e o seu papel no encaminhamento das questões educacionais. É a mediação da discussão nacional, daqueles que estão envolvidos com a prática, que pode dar a direção mais correta para o momento histórico. 


\title{
Notas:
}

1. O Encontro Nacional de "Reformulação dos Cursos de Preparação de Recursos Humanos para a Educação" foi promovido pela Secretaria de Educação do Ensino Superior/MEC em novembro de 1983, em Belo-Horizonte,MG.

2. A Comissão Nacional de Reformulação dos Cursos de Formação do Educador - Conarcfe foi instituída pelos educadores e estudantes presentes no Encontro Nacional de Belo Horizonte, em novembro de 1983, com a finalidade de dar continuidade ao processo de discussão sobre a reformulação dos cursos de formação do educador e acompanhar as ações do MEC junto aos cursos de licenciaturas. A Conarcfe atuou até 1990 quando se transformou na Associação Nacional pela Formação dos Profissionais da Educação Anfope.

3. Compõem a Comissão de Especialistas de Ensino de Pedagogia da SESu/ MEC os Professores Leda Scheibe (UFSC), Márcia Angela da Silva Aguiar (UFPE), Celestino Alves da Silva Júnior (UNESP), Tizuko Morchida Kishimoto (USP), Zélia Milléo Pavão (PUC/PR).

\section{The formation of the education professional in Brazil: The Pedagogy Course in question}

\begin{abstract}
The aim of this paper is to contribute for a better understanding of the Pedagogy Course present situation, in the realm of the undergraduate teaching level, and of the difficulties for the implantation of the new curriculum directives for this Course. Initially, we contextualize the debate concerning the directives, considered the alterations which are being proposed for the whole level, giving also a brief history of the Pedagogy Course in Brazil. The process of identity affirmation of the education professional and the building of the teaching practice as a basic ground for his formation are followed by some directives, which are indicated by the present Brazilian historical moment for the formation of the pedagogue.
\end{abstract}

\section{Bibliografia}

AGUIAR, Márcia A. "Institutos superiores de educação na nova LDB". In: BRZEZINSKI, I. (org.). LDB interpretada: Diversos olhares se entrecruzam. São Paulo: Cortez, 1997. 
. "Institutos Superiores de Formação de Professores: Novo modismo na educação nacional?". Anais VII Endipe. Goiânia: UFG/ UCG, 1994.

. "Sistemas universitários na América Latina e as orientações políticas das agências internacionais". In: CATANI, A.M. (org.). Novas perspectivas nas políticas de educação superior na América Latina no limiar do século XXI. São Paulo: Autores Associados, 1998.

ANFOPE, Boletim da ANFOPE, Campinas, SP, ano V, no 11, agosto 1999 http://lite.fae.unicamp.br/anfope

BISSOLLI DA SILVA, Carmem Silvia. Curso de pedagogia no Brasil: História e identidade. Dissertação de mestrado. Marília: Unesp, 1999.

GADOTTI, Moacir. Educação e compromisso. Campinas: Papirus, 1985.

REIS SILVA Jr. João; SGUISSARDI, Valdemar. "Reconfiguração da educação superior no Brasil e redefinição das esferas pública e privada nos anos 90". Revista Brasileira de Educação no ${ }^{0}$ 10. São Paulo: Anped, jan./fev./mar./abr. 1999a.

. Novas faces da educação superior no Brasil. Bragança Paulista: Edusf, 1999b.

SACRISTÁN, J.G. O currículo: Uma reflexão sobre a prática. $3^{\text {a }}$ ed. Porto Alegre: Artmed, 1998. 